\title{
Concomitant autoimmune thyroiditis and primary hyperparathyroidism - random association? Two cases report
}

\author{
Ioana Vasiliu ${ }^{1}$, Carmen Vulpoi ${ }^{1}$, Ioana Armaşu ${ }^{1^{*}}$, Cipriana Ștefănescu ${ }^{2}$, Radu Dănilă ${ }^{3}$, \\ Delia Gabriela Ciobanu ${ }^{4}$, Iulia Crumpei ${ }^{1}$, Cristina Preda ${ }^{1}$ \\ ${ }^{1}$ Department of Endocrinology. "Sf. Spiridon" Emergency Clinical Hospital lași, Romania, "Grigore T. \\ Popa" University of Medicine and Pharmacy lasi, Romania, ${ }^{2}$ Department of Nuclear Medicine, "Sf. \\ Spiridon" Emergency Clinical Hospital lași, Romania, "Grigore T. Popa" University of Medicine and \\ Pharmacy lasi, Romania, ${ }^{3}$ Department of General Surgery, "Sf. Spiridon" Emergency Clinical Hospital \\ lași, Romania, "Grigore T. Popa" University of Medicine and Pharmacy lasi, Romania, ${ }^{4}$ Department of \\ Pathology, "Sf. Spiridon" Emergency Clinical Hospital lași, Romania, "Grigore T. Popa" University of \\ Medicine and Pharmacy lasi, Romania
}

\begin{abstract}
Autoimmune thyroiditis and primary hyperparathyroidism are frequent diseases, mainly affecting postmenopausal women. The association between the two pathologies has been described in the literature but the underlying mechanism is not yet elucidated. We present two female patients with autoimmune thyroiditis who developed primary hyperparathyroidism. Both had normal thyroid function, high antithyroid antibodies, and high PTH and calcium values. Thyroid ultrasonography and ${ }^{99 \mathrm{~m}} \mathrm{Tc}-\mathrm{MIBI}$ scintigraphy localized the lesion but only one patient underwent surgery. Vitamin $D$ and selenium values were normal or slightly reduced. Both patients had osteoporosis, treated with bisphosphonates. Their evolution is, till now, satisfactory. More theories are trying to explain the correlation between autoimmune thyroiditis and primary hyperparathyroidism: the inflammatory process, the high TSH or PTH values, high calcium, low vitamin D. The possible selenium intervention would correlate environmental and genetic factors. However, all these theories are controversial and not yet proved by experimental or randomized clinical studies.
\end{abstract}

Keywords: autoimmune thyroiditis, primary hyperparathyroidism, selenium, vitamin $D$, calcium

\section{Introduction}

Chronic autoimmune thyroiditis (AIT) is one of the most prevalent autoimmune diseases and affects more than $10 \%$ of females and $2 \%$ of males. It is a complex and an organ-specific T-cell mediated disease [1].

Received: September 2015; Accepted after review: September 2015; Published: September 2015.

${ }^{*}$ Corresponding author: loana Armaşu, Department of Endocrinology of "Sf. Spiridon" Emergency Clinical Hospital lași, Romania, "Grigore T. Popa" University of Medicine and Pharmacy lasi, Romania.

E-mail: armasu.i.ioana@gmail.com
Etiology of autoimmune thyroiditis combines genetic and environmental factors. Genetic factors dominate, and influence with about $80 \%$ on the occurrence of immunity. Some HLA genes (HLA-DR3, HLA-DR4, HLADR5 and HLA-DQA) and non-HLA genes (cytotoxic T-lymphocyte antigen 4 -CTLA-4, CD40 gene, gene for protein tyrosine phosphatase 22 -PTPN22, thyroglobulin and TSH gene) are involved. $20 \%$ of etiology is attributed to environmental factors (smoking, iodine intake, selenium deficiency, pollution, infectious conditions, physical and emotional stress) and physiological states (puberty, rapid growth, pregnancy, menopause, aging, female gender) [2, 3]. 
One of the environmental factors implicated in the etiology of autoimmune thyroiditis is selenium. Se is an important element that exerts its effects through selenoproteins. Selenium was shown to have an important role in lymphocytic chronic thyroiditis. Most authors consider that $\mathrm{Se}$ affects the autoimmune system by controlling the production of ROS (Reactive Oxygen Species) and Se supplementation determines a stimulating activity on glutathione peroxidases and thyoreductases. Another path in which $\mathrm{Se}$ is involved in autoimmune thyroiditis may be by inhibiting the expression of HLA-DR molecules [4]. There is experimental evidence on the link between Se and $T$ cells (the decrease of antithyroglobulin antibodies is associated with a decline in lymphocytic infiltration of the thyroid after $\mathrm{Se}$ supplementation [5].

Current, there are no ways to stop the autoimmune process in chronic thyroiditis; the treatment with levothyroxine only addresses to the consequences of autoimmune aggression. Given current knowledge, the therapy with Se, in order to reduce aggression and prevention of autoimmune thyroid dysfunction, remains the only therapeutic alternative whose effectiveness needs to be supported by more evidence.

Primary hyperparathyroidism is a problem with increasing frequency in the endocrinological practice, especially after 55 years of age. In general population, the prevalence is between $0.1-0.3 \%$, while in 55 75 years old postmenopausal women it reaches $2-5 \%[6,7]$.

The increment of the prevalence in the last decades may be due to the more systematic dosage of calcium, permitting an earlier diagnostic, in the subclinical stage [8]. This is sustained by the fact that, contrary to the classical clinical manifest picture of the disease, nowadays most of these cases $(80 \%)$ are asymptomatic [9].

Besides the known association of primary hyperparathyroidism (PHPT) with other endocrine tumors in the multiple endocrine neoplasia, an association of PHPT with diffuse thyroid disorders (autoimmune thyroiditis, Graves' disease) is quoted in the literature [7].
We present two cases associating PHPT and AIT and their probable interconnections.

\section{Case reports}

\section{Case 1}

Female patient, 67 years old, treated from 2005 for osteoporosis with bisphosphonates, was diagnosed in 2013 with autoimmune thyroiditis (high antibodies: TPOAb $1000 \mathrm{IU} / \mathrm{I}$ ) with normal thyroid function: TSH $1.99 \mu \mathrm{IU} / \mathrm{ml}$ $(\mathrm{N}=0.4-4 \mu \mathrm{lU} / \mathrm{ml})$, fT4 $0.997 \mathrm{ng} / \mathrm{ml} \quad(\mathrm{N}=0.89$ $1.76 \mathrm{ng} / \mathrm{ml}$ ). She was periodically monitored for her osteoporosis. In 2013, biological data revealed had high calcium values (10.85 $\mathrm{mg} / \mathrm{dl}, \quad \mathrm{N}=8.4-10.2 \mathrm{mg} / \mathrm{dl})$ with normal high PTH $(65.7 \mathrm{pg} / \mathrm{ml}, \mathrm{N}=11-67 \mathrm{pg} / \mathrm{ml})$, suggestive for primary hyperparathyroidism. She had no complains and monitoring was decided. In May 2014 she presented more specific biological values $(\mathrm{Ca}=11.08 \mathrm{mg} / \mathrm{dl}, \mathrm{PTH}=113$ $\mathrm{pg} / \mathrm{ml})$, with worsening of the osteodensitometric parameters: T-score spine $=-3.6$, hip -2.6 . Thyroid ultrasonography revealed a hypoechoic right infero-posterior nodule of $0.6 / 0.6 / 0.5 \mathrm{~cm}$, suggestive for parathyroid adenoma (Figure 1).

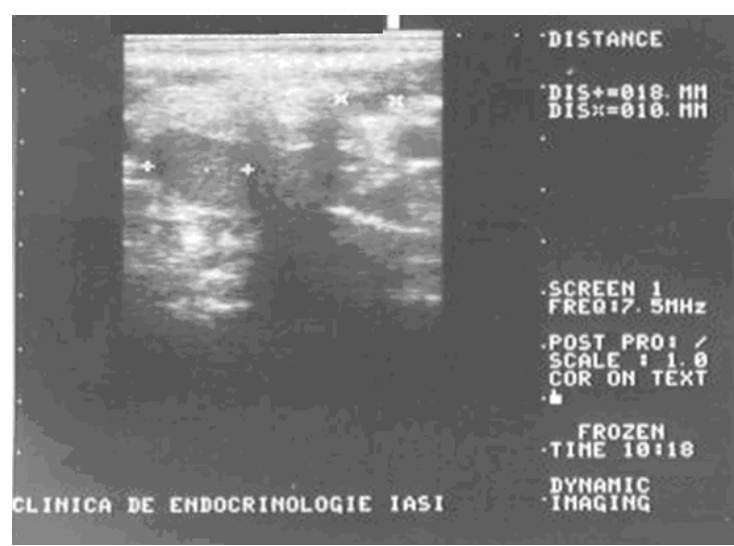

Fig.1. Thyroid ultrasonography. Hypoechoic right infero-posterior nodule

Dual phase ${ }^{99 \mathrm{~m}} \mathrm{Tc}$-sestamibi parathyroid scintigraphy described high uptake in the precocious period of the region of the suspected parathyroid lesion, without efflux in the late period - image of parathyroid adenoma (Figure 2). 


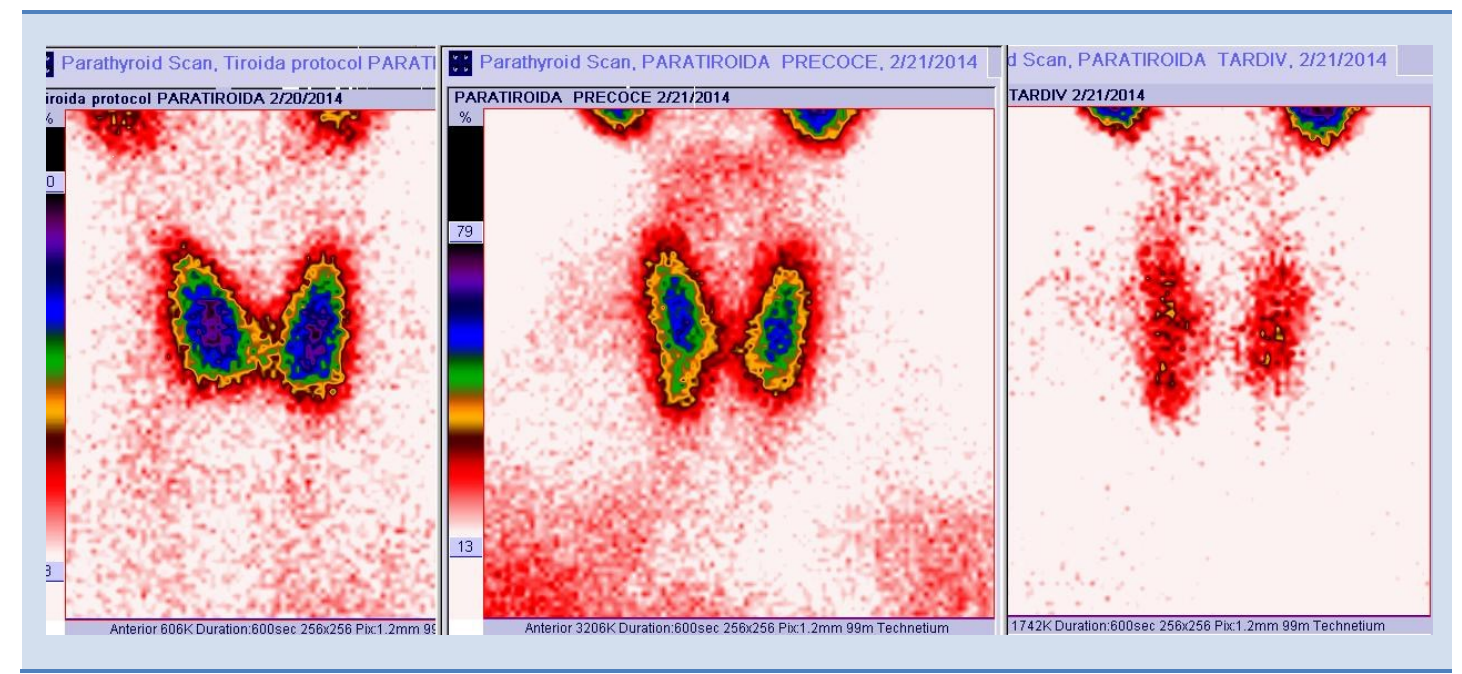

Fig. 2. 99mTC-MIBI scintigraphy. Parathyroid adenoma at the inferior right pole

Surgery was decided (ablation of the right inferior nodule). Pathology confirmed a parathyroid adenoma. In December 2014 phospho-calcic parameters were normalized: PTH $=55.27 \mathrm{pg} / \mathrm{ml}, \mathrm{Ca}=9.92 \mathrm{mg} / \mathrm{dl}$, normal vitamin $\mathrm{D}(32.58 \mathrm{ng} / \mathrm{ml}, \mathrm{N}>30 \mathrm{ng} / \mathrm{ml})$. Thyroid function was normal (TSH $=1.52 \mu \mathrm{lU} / \mathrm{ml}$, fT4=1.14 $\mathrm{ng} / \mathrm{ml}$ ), with persistent high antibodies, although significantly ameliorated $(T P O A b=73.3 \mathrm{IU} / \mathrm{ml})$. Thyroid ultrasonography described normal thyroid volume $(7.2 \mathrm{ml})$, intense hypoechogenicity and normal vascularisation. She was part of a screening of selenium values in patients with normofunctioning autoimmune thyroiditis.

She was part of a study evaluating selenium status in patients with autoimmune thyroiditis with normal function. The study consisted in selenium and thyroid parameters evaluation at a 3 months interval. Patients were randomized in a treated $(100 \mu \mathrm{g} / \mathrm{d}$ selenium) and a non-treated group. All patients signed an informed consent before being included in the study.

Our patient's selenium value was low normal $63 \mu \mathrm{g} / \mathrm{l}, \quad \mathrm{N}=60-120 \mu \mathrm{g} / \mathrm{l}$. On randomization, she was part of the non-treated group. Three months after, her selenium was normal, but still in the inferior half $(90 \mu \mathrm{g} / \mathrm{l})$, thyroid antibodies remained positive but at lower values (TPOAb $=58.4 \mathrm{IU} / \mathrm{l})$. Thyroid function remained normal $(\mathrm{TSH}=1.56 \mu \mathrm{lU} / \mathrm{ml}$, fT $4=1.15 \mathrm{ng} / \mathrm{ml}$ ).

\section{Case 2}

55 years old female patient, with antecedents of acute pancreatitis in 2006 and gastric ulcerus, associating blood hypertension and type 2 diabetes mellitus, was addressed to the endocrinological department in June 2014 for high calcium values. Biological data confirmed a primary hyperparathyroidism: high total $(11.12 \mathrm{mg} / \mathrm{dl})$ and ionic calcium (1.5 $\mathrm{mmol} / \mathrm{l})$ with high PTH $(132.4 \mathrm{pg} / \mathrm{ml})$ and low vitamin $D(23.45 \mathrm{ng} / \mathrm{ml})$. Excepting for the forearm ( $T$ score -2.9 ), osteodensitometry was in the osteopenic limits ( $T$ score spine $-1.7, T$ score hip -1.1). Thyroid ultrasonography revealed in the inferior part of the right lobe a solid nodule of $0.7 / 0.7 / 0.6 \mathrm{~cm}$, possible a parathyroid adenoma (Figure 3). 

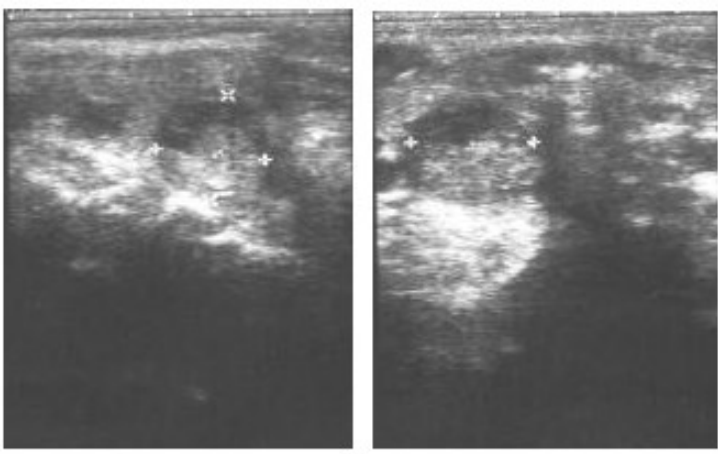

Fig. 3. Thyroid ultrasonography. Solid right posteroinferior nodule
Thyroid aspect was inhomogenous, predominently hypoechoic. Normal thyroid volume $(9.77 \mathrm{ml})$, with normal vascularization.

Thyroid function was normal $\mathrm{TSH}=2.3$ $\mathrm{uUl} / \mathrm{ml}, \mathrm{fT} 4=1.25 \mathrm{ng} / \mathrm{dl}$, with $\mathrm{fT} 3$ at the superior limit of the normal $5.04 \mathrm{pg} / \mathrm{ml},(\mathrm{N}=2.2-5 \mathrm{pg} / \mathrm{ml})$, and slightly high thyroid antibodies (TPOAb=52.2 IU/l). Parathyroid scintigraphy described a discrete asymmetry of captation at the inferior pole of the right thyroid lobe, which could suggest a parathyroid hyperplasia (Figure 4).

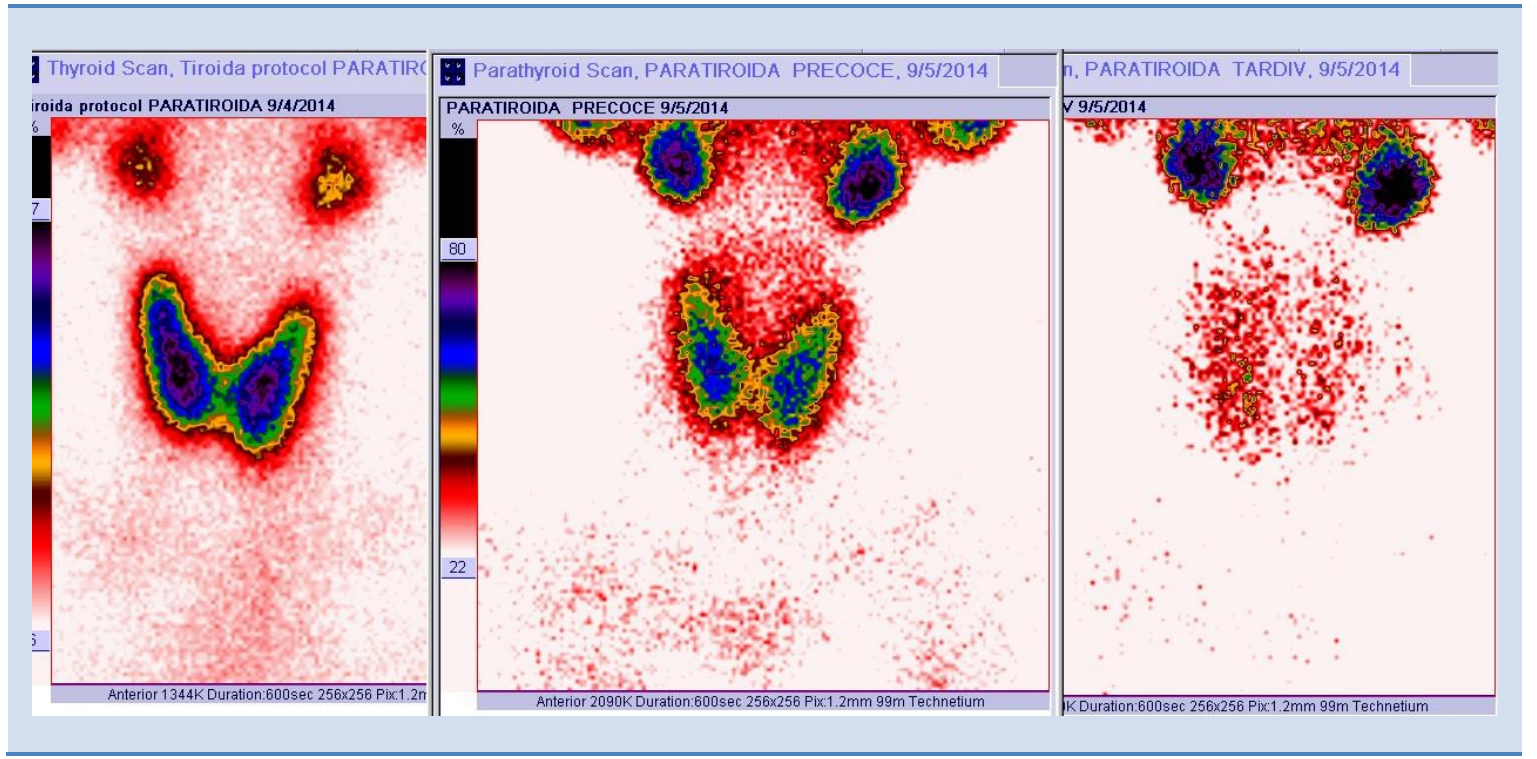

Fig. 4. 99mTc-MIBI scintigraphy. Observation parathyroid hyperplasia at the inferior right pole

Despite the antecedents, which could be attributed to hyperparathyroidism, and the repeated high PTH and calcium values, patient refused surgery, and a bisphosphonates and vitamin $D$ treatment was started. At the last reevaluation, her general status was good, but with higher PTH $(151.9 \mathrm{ng} / \mathrm{dl})$ and calcium (total Ca $11.21 \mathrm{mg} / \mathrm{dl}$, ionic Ca $1.6 \mathrm{mmol} / \mathrm{l}$ ) values. Vitamin $D$ ameliorated, remaining at the inferior limit of the normal range $(28.52$ $\mathrm{ng} / \mathrm{ml}$ ).

She was included on the selenium screening group, after randomisation remaining in the group without treatment. Her selenium values were within the normal limits at both determination (100, respectively 150 $\mu \mathrm{g} / \mathrm{ml}$ ), as well as the thyroid function (TSH=2.59 $\mu \mathrm{lU} / \mathrm{ml}$, fT4 $1.27 \mathrm{ng} / \mathrm{dl}$. TPOAb remained practically stable $67.7 \mathrm{IU} / \mathrm{l}$.

\section{Discussions}

We presented two cases of autoimmune thyroiditis associated with primary hyperparathyroidism. Both patients were menopaused females, aged of 67, and respectively 55 years. AIT, as well as PHPT, is more frequent in women after menopause: 10$60 \%$ women develop hypothyroidism, and 2$5 \%$ primary hyperparathyroidism (7).

In the first case, AIT and osteoporosis were diagnosed 8 years before PHPT. Surgery cured parathyroid adenoma and there after the evolution was satisfactory. In the second case it is difficult to say which disease was the first, the antecedents of pancreatitis and gastric ulcers suggesting an undiagnosed 
hyperparathyroidism. In spite of the high calcium and PTH values she had yet a good evolution with only bisphosphonates. Both patients had high TPOAb, normal thyroid function, and normal or slightly low values of selenium and vitamin D. It is difficult to say if the association is a random or a causal one, and which of the two diseases have triggered the other.

The association between thyroid diseases and PHPT was first described in 1947 (Kissin $M$ \& Bakst $H$, quoted by 7 ), with a prevalence evaluated, function of the author, between 20 and $70 \%$ [10]. Among these, AIT association with PHPT was find in 3.8-17.6\% [11]. Most of the studies pointed on the difficulties of diagnostic and management issued by this association. The inflammatory process found in AIT may interfere the uptake mechanism of ${ }^{99 \mathrm{~m}} \mathrm{Tc}-\mathrm{MIBI}$, giving a false negative image [12]. One of our patients (case 2), in spite of the clear biological picture and the ultrasonographic image of a well delimited postero-inferior nodule, had only a suggestion of parathyroid hyperplasia at the scintigraphy, possibly related to this interference.

The underlying mechanism of the AIT PHPT association is not yet understood. Earlier experimental studies in rats have shown that chronic high TSH induces parathyroid hyperplasia and high PTH values. However, even at a large interval after TSH normalization, studies showed that patients with autoimmune thyroiditis can develop hyperparathyroidism [13]. It is possible that the chronic inflammation may exert an irritating effect of the parathyroid tissue, inducing the release of PTH [7, 13], but, as we shall see further, a more pertinent hypothesis is that the autoimmune process, by its cytokine and stimulating factors, may account for this association.

The prevalence of thyroid diseases in patients with primary PHPT have been found independent of the influence of age, sex, or PTH values. This conducted to the speculation that high calcium values rather than other factors may have a pathogenic role, hypothesis sustained by some experimental data. High PTH values were also discussed as a possible proliferation factor, but the prevalence of thyroid diseases is higher in primary than in secondary PHPT, while PTH values are significantly higher in the secondary form. Other growth factors, as EGF (epithelial growth factor) or IGF1, increased in PHPT, have also a goitrogenic effect [14].

Recent studies have shown that vitamin $D$ deficiency is associated with a higher prevalence of Hashimoto's thyroiditis, suggesting that low vitamin $D$ may play a role in the development of thyroid autoimmunity. Vitamin $D$ plays an important role in autoimmunity. It regulates $\mathrm{T}$ helper lymphocytes (Th1, Th2, Th17) and their cytokine secretion (as IFN Y), which are involved in the development of thyroid autoimmunity [15]. A correlation between AIT and reduced vitamin $D$ action (as some polymorphisms of vitamin $\mathrm{D}$ receptor gene, vitamin $\mathrm{D}$ binding proteins, $1 \alpha-$ and 25 hydroxylase) has also been demonstrated [16]. On the other side, type 2 deiodinase activity has been demonstrated in the mouse skeleton and is induced by vitamin $D$, suggesting a closer relationship between thyroid hormones and vitamin D [17]. Taking in account these considerations, vitamin $D$ supplementation could be beneficial in reducing the risk of autoimmune thyroiditis. Our second patient had moderately reduced levels of vitamin D. However, it was a mild deficiency, most probably with no or only a minor role in promoting thyroid autoimmunity. Thyroid gland has a high concentration of selenium, as constitutive part of type 1 and 2 deiodinases (Dio 1 and 2), which convert thyroxine (T4) to triiodothyronine (T3); Gpx 1 and 4 , which protect thyreocytes against $\mathrm{H} 2 \mathrm{O} 2$ released during thyroglobulin iodination; $\mathrm{Gpx} 3$, regulating $\mathrm{H} 2 \mathrm{O} 2$ concentration in the lumen of thyroid follicle; selenoprotein $\mathrm{P}$ and Txnrd 1, having an antioxidant effect [18].

In normal nutritional conditions, the liver is the primary source of plasmatic T3, due to liver deiodination of T4 by Dio1 (which actually contributes to the release of T3 by the thyroid). In Se deficiency, the primary source of T3 is the thyroid by increasing thyroid activity of Dio1 which allows maintaining normal concentrations of plasma T3 despite reduced activity of hepatic Dio1 [19].

Selenium deficiency leads to a decrease in GPx activity that results in the accumulation of 
$\mathrm{H}_{2} \mathrm{O}_{2}$ in the thyroid and thus enhancing apoptosis. Since $\mathrm{H}_{2} \mathrm{O}_{2}$ is essential in the synthesis of $\mathrm{T} 3$ and $\mathrm{T} 4$, its accumulation could be the activator of increased thyroid production of T3 and T4. Probably Dio 1 is required to maintain an optimum T4/T3 balance in these conditions [19].

We have mentioned the correlation between deiodinase activity and vitamin $D$. Between the numerous known selenoproteins at least one ( $p 15)$ has been identified in both thyroid and parathyroids, with role in $\mathrm{H} 2 \mathrm{O} 2$ degradation [20]. This may be one of the less investigated pathways of the correlation between autoimmune thyroiditis and bone metabolism, also implicating selenium, whose role in thyroid autoimmunity have already been proven.

The normal plasma concentrations of Se range between 60 and $120 \mu \mathrm{g} / \mathrm{l}$, being related to its intake. In order to avoid toxic effects, the daily dose should not exceed $400 \mu \mathrm{g} /$ day [21]. There is a great variability depending of the geographical area, related with the differences of soil content in selenium. Both our patients had normal selenium values, with slight

\section{References}

1. Chistiakov DA. Immunogenetics of Hashimoto's thyroiditis. J Autoimmune Dis 2005; 2:1 doi:10.1186/1740-2557-2-1.

2. Baretić M. 100 years of Hashimoto thyroiditis, still an intriguing disease. Acta Med Croatica 2011; 65:453-457.

3. Duntas LH. Environmental factors and thyroid autoimmunity. Ann Endocrinol (Paris) 2011; 72:108-113.

4. Balazs C, Kaczur V. Effect of selenium on HLADR expression of thyreocytes. Autoimmune Dis 2012; $\quad$ Article ID 374635 doi:10.1155/2012/374635.

5. Xue $H$, Wang $W$, Li $Y$, et al. Selenium upregulates CD4CD25 regulatory $T$ cells in iodine-induced autoimmune thyroiditis model of NOD.H-2 mice. Endocr J 2010; 57:595-601.

6. Tee MC, Chan SK, Nguyen $V$, et al. Incremental value and clinical impact of neck sonography for primary hyperparathyroidism: a risk-adjusted analysis. Can J Surg 2013; 56:325-331. variations between the two determinations. Even if a pathogenic role is probable, it cannot be demonstrated at this moment.

\section{Conclusions}

It is not clear yet if the coexistence of AIT and PHPT is a random association or the result of interconnected pathological mechanisms. Our cases illustrate the correlations of the two diseases. It is difficult to say that this connection is causal, but the low vitamin $D$, high thyroid autoantibodies, high calcium and $\mathrm{PTH}$, and the variations of selenium seem to be at least interdependent factors. All these major players influence the morphology and function of thyroid and parathyroids and may interact in a complex manner.

In terms of clinical practice the coexistence of AIT and PHPT makes difficult the diagnosis and may affect the natural evolution of both diseases. Further researches are necessary in order to identify the eventual link between AIT and PHPT.

7. Ignjatovic VD, Matovic MD, Vukomanovic VR, Jankovic SM, Džodić RR. Is there a link between Hashimoto's thyroiditis and primary hyperparathyroidism? A study of serum parathormone and anti-TPO antibodies in 2267 patients. Hell J Nucl Med 2013; 16:86-90.

8. Marcocci C, Mazzeo S, Bruno-Bossio G, et al. Preoperative localization of suspicious parathyroid adenomas by assay of parathyroid hormone in needle aspirates. Eur J Endocrinol 1998; 139:72-77.

9. Vitetta GM, Neri P, Chiecchio A, et al. Role of ultrasonography in the management of patients with primary hyperparathyroidism: retrospective comparison with technetium-99m sestamibi scintigraphy. J Ultrasound 2014; 17:1-12

10. Masatsugu T, Yamashita $H$, Noguchi $S$, et al. Thyroid evaluation in patients with primary hyperparathyroidism. Endocr $J$ 2005; 52:177182.

11. Zheng $Y X, X u$ SM, Wang $P$, Chen $L$. Preoperative localization and minimally invasive management of primary hyperparathyroidism concomitant with thyroid 
disease. J Zhejiang Univ Sci B 2007; 8:626631.

12. Boi F, Lombardo C, Cocco MC, et al. Thyroid diseases cause mismatch between MIBI scan and neck ultrasound in the diagnosis of hyperfunctioning parathyroids: usefulness of FNA-PTH assay. Eur J Endocrinol 2012; 168:49-58.

13. Cating-Cabral MT, Cabungcal AC, Villafuerte CV $3^{\text {rd }}$, Añel-Quimpo J. Primary hyperparathyroidism due to an intrathyroidal parathyroid adenoma associated with chronic lymphocytic thyroiditis. BMJ Case Rep 2012; doi: 10.1136/bcr-2012-006198.

14. dell'Erba $L$, Baldari $S$, Borsato $N$, et al. Retrospective analysis of the association of nodular goiter with primary and secondary hyperparathyroidism. Eur J Endocrinol 2001; 145:429-434.

15. Wang J, Lv S, Chen G, et al. Meta-analysis of the association between vitamin $D$ and autoimmune thyroid disease. Nutrients 2015; 7(4):2485-2498.
16. Muscogiuri G, Mitri J, Mathieu $C$, et al. Mechanisms in endocrinology: vitamin $D$ as a potential contributor in endocrine health and disease. Eur J Endocrinol 2014; 171(3):101110.

17. Arslan MS, Topaloglu $O, U$ can B, et al. Isolated vitamin $D$ deficiency is not associated with nonthyroidal illness syndrome, but with thyroid autoimmunity. Scientific World J 2015; doi:10.1155/2015/2398152015.

18. Negro R. Selenium and thyroid autoimmunity. Biol 2008; 2:265-273.

19. McCann JC, Ames BN. Adaptive dysfunction of selenoproteins from the perspective of the triage theory: why modest selenium deficiency may increase risk of diseases of aging. FASEB J 2011; 25:1793-1814.

20. Köhrle J, Jakob F, Contempré B, Dumont JE. Selenium, the thyroid, and the endocrine system. Endocr Rev 2005; 26:944-984.

21. Drutel A, Archambeaud F, Caron P. Selenium and thyroid gland: more good news for clinicians. Clin. Endocrinol 2013; 78: 155-164. 